\title{
Financiamento da infraestrutura de transportes
}

[Transport infrastructure financing]

\author{
Alessandro V. M. Oliveira, Frederico Araujo Turolla* \\ Instituto Tecnológico de Aeronáutica (ITA), Brazil, ESPM, Brazil
}

Submitted 9 Mar 2011; received in revised form 9 Dec 2011; accepted 26 Jan 2012

\section{Resumo}

O setor de transportes é marcado por externalidades e por características típicas do setor de infraestrutura. Este artigo discute o financiamento da expansão da infraestrutura setorial, incluindo o investimento direto estrangeiro e considerando os aspectos institucionais e regulatórios subjacentes, relacionados às características econômicas do setor.

Palavras-Chave: infraestrutura; transportes; financiamento; regulação; falha de mercado; investimentos diretos estrangeiros.

\section{Abstract}

The transportation sector is marked by the presence of externalities and by typical characteristics of the infrastructure sector. This article discusses the financing of the expansion of sector infrastructure, including foreign direct investment and taking into account the underlying institutional and regulatory dimensions, related to the economic characteristics of the sector

Key words: transportation; financing; regulation; market failure; foreign direct investment.

* Corresponding Author. Email: fturolla@espm.br.

\section{Recommended Citation}

Oliveira, A. V. M. and Turolla, F. A. (2013) Financiamento da infraestrutura de transportes. Journal of Transport Literature, vol. 7, n. 1, pp. 103-126.

- JTL/RELIT is a fully electronic, peer-reviewed, open access, international journal focused on emerging transport markets and published by BPTS - Brazilian Transport Planning Society. Website www.transport-literature.org. ISSN 2238-1031.

This paper is downloadable at www.transport-literature.org/open-access. 


\section{Introdução}

A indústria de infraestrutura é central para o desenvolvimento econômico de qualquer país. O aumento da penetração e a qualidade das redes de transportes, telecomunicações, energia, saneamento básico e outras constituem veículo indispensável do progresso das nações, assim como da redução da pobreza, da proteção do meio ambiente e da inclusão no ambiente social e no mundo digital. Conforme Calderon e Serven (2004), há elevados custos econômicos e sociais associados ao subdesenvolvimento de infraestrutura, em especial quanto às redes de transporte e de energia elétrica, mas também quanto à insuficiência das redes de saneamento, e a baixa competição nas telecomunicações.

Apesar da elevada importância econômica e social, há importantes deficiências de cobertura em setores com altas externalidades. Embora haja avanços em direção ao acesso universal à energia elétrica e à telefonia celular, o restante das telecomunicações, os transportes e o saneamento permanecem com redes cuja penetração está muito aquém do desejável.

Um aspecto interessante é a comparação da situação brasileira frente às demais nações. Pelos diversos indicadores, a situação não é animadora. Por exemplo, uma das comparações pode ser feita a partir do índice de infraestrutura do The Global Competitiveness Report, sumariado na Figura 1.

Em função da precariedade da infraestrutura de transportes no Brasil, os custos de logística chegam a níveis médios bastante elevados em comparação aos demais países. Segundo estimativa de Jose Luis Guasch e Joseph Kogan, apresentada em Andrés, Guasch, Haven e Foster (2008, p. 9), o custo de logística médio como percentual do valor dos produtos no Brasil é de $26 \%$, contra uma média de $9 \%$ nos países da Organização para a Cooperação e Desenvolvimento Econômico (OCDE), ou 18\% no Chile. Assim, a produção de qualquer item no território brasileiro é fortemente penalizada frente aos seus concorrentes, não bastasse o elevado peso da tributação que grava os produtos brasileiros relativamente à média dos demais países. 


\begin{tabular}{|l|c|}
\hline & Ranking do Brasil \\
\hline Brasil - posição geral no ranking & $53^{\circ} \mathrm{em} 142$ países \\
\hline Brasil - Infraestrutura - Geral & $64^{\circ} \mathrm{em} 142$ países \\
\hline Qualidade das rodovias & $118^{\circ} \mathrm{em} 142$ países \\
\hline Qualidade da infraestrutura ferroviária & $91^{\circ} \mathrm{em} 142$ países \\
\hline Qualidade da infraestrutura portuária & $130^{\circ} \mathrm{em} 142$ países \\
\hline Qualidade da infraestrutura de transporte aéreo & $122^{\circ} \mathrm{em} 142$ países \\
\hline Aviação - assentos disponíveis x km por semana & $9^{\circ} \mathrm{em} 142$ países \\
\hline Qualidade da oferta de eletricidade & $69^{\circ} \mathrm{em} 142$ países \\
\hline Linhas telefônicas fixas por 100 habitantes & $57^{\circ} \mathrm{em} 142$ países \\
\hline Linhas telefônicas móveis por 100 habitantes & $66^{\circ} \mathrm{em} 142$ países \\
\hline
\end{tabular}

\section{Figura 1 - The Global Competitiveness Report 2011-2012, posição do Brasil em} indicadores selecionados de competitividade

Fonte: The Global Competitiveness Report 2011-2012, World Economic Forum.

Considerando os pesados desafios que o Brasil terá que enfrentar nos próximos anos, particularmente nas áreas de transportes, a questão do financiamento da expansão da infraestrutura existente assume importância fundamental. Um encaminhamento adequado desta questão trará benefícios inegáveis em termos de desenvolvimento social e econômico, redução da pobreza, promoção da competitividade, geração de empregos e de renda, capilarização e interiorização do desenvolvimento, entre outros importantes objetivos.

Este artigo discute os aspectos econômicos das questões relativas ao financiamento da infraestrutura de transportes. $\mathrm{O}$ artigo foi organizado em cinco seções além desta introdução. A segunda seção apresenta as características econômicas que definem os setores de infraestrutura. A terceira seção desenvolve o papel da regulação e o financiamento setorial. A quarta seção discute o financiamento da infraestrutura e o ambiente institucional brasileiro neste particular. A quinta seção apresenta uma breve consideração sobre a participação privada e sobre os investimentos diretos estrangeiros em infraestrutura no Brasil. Finalmente, a última seção apresenta comentários finais. 


\section{Características econômicas da infraestrutura}

A indústria de infraestrutura possui uma peculiaridade que a torna fundamental para o desenvolvimento econômico de qualquer país, qual seja, sua capacidade de gerar externalidades positivas ou de reduzir as externalidades negativas tipicamente associadas aos sistemas de transporte. As externalidades estão associadas a impactos, positivos ou negativos, de uma atividade econômica, sem a devida compensação ao agente gerador do impacto. As externalidades negativas dizem respeito a congestionamento de tráfego, poluição, atrasos na entrega e outros impactos que compõem o custo final dos produtos nas mais diversas cadeias produtivas. A redução desses impactos corresponde, conforme Blum (1998), a benefícios líquidos. As externalidades positivas geradas pelo setor de transportes, por sua vez, incluem ganhos de eficiência para a economia como um todo e vantagens sociais da conexão de regiões e de segmentos de atividade econômica.

Além da presença de importantes externalidades, o setor de transportes possui algumas características econômicas relativamente bem definidas, em particular nos segmentos de infraestrutura. Em termos econômicos, o setor de infraestrutura caracteriza-se fundamentalmente pela presença de custos fixos elevados em capital específico (BID, 1997). Tais custos produzem um dilema econômico entre eficiência produtiva e alocativa, enquanto a especificidade de capital produz sub-incentivo ao investimento.

A importância relativa dos custos fixos faz com que o conjunto de vetores de produção relevante recaia sobre a faixa em que o custo médio é declinante. Economias de escala dessa natureza, quando consideradas em um contexto de monoprodução, identificam, conforme Baumol (1986), um monopólio natural. O conceito pode ser estendido para a presença de economias de escopo, em um contexto de multiprodução, para a idéia de subaditividade de custos como desenvolvida por Braeutigam (1989). Neste caso, não há necessidade de economia de escala global, bastando que uma firma produza um vetor y de produtos com custo menor que o somatório dos custos de um conjunto j de firmas.

Dada a estrutura de monopólio natural, a maior eficiência produtiva pode ser conseguida através da operação de um produtor único. Entretanto, as distorções alocativas resultantes do poder de monopólio precisam ser controladas através de algum mecanismo. Eliminando-se 
pelo critério de eficiência produtiva a possibilidade de competição direta, a obtenção de eficiência alocativa requer o emprego de competição pelo direito à franquia para servir um determinado mercado (competição de Demsetz), ou ainda um mecanismo de regulação. Na prática é possível combinar as duas alternativas, com a realização de leilões pela franquia e o estabelecimento de mecanismos de regulação.

Um recurso essencial, também chamado de infraestrutura essencial (essential facility), consiste em um recurso, em geral um tipo de infraestrutura de um dado setor, que permite acesso a um grupo de usuários ou consumidores, mas cuja duplicação é economicamente inviável. Os recursos essenciais são, na prática, gargalos que impossibilitam o acesso a determinados grupos de consumidores, exceto por uma única firma que controla o recurso. A partir da inviabilidade da oferta pelos concorrentes, tem-se a geração de potenciais danos ao consumidor, quer seja pela restrição do portfólio de alternativas disponíveis, quer seja pelo arrefecimento da competição. Trata-se de um problema tipicamente relevante, sobretudo no caso de existência de competição entre uma firma estabelecida verticalizada, detentora do recurso, e firmas entrantes, que necessitam do mesmo para operarem no mercado - o que abre espaço para práticas anticompetitivas e exercício do poder de mercado, com potencial prejuízo ao bem-estar econômico. É, portanto, um claro objeto de atenção regulatória.

Sabe-se que a desregulamentação dos mercados de transporte, em muitos países ao redor do mundo, permitiu uma interação competitiva ampliada entre as operadoras, que conduziu a melhorias substanciais na eficiência produtiva e alocativa. Porém, foi justamente a presença de recursos essenciais, como os aeroportos, um dos fatores que limitou o alcance e o sucesso destas reformas, juntamente com a persistência de intervenção redundante e de poder de mercado de firmas estabelecidas. A mesma análise vale para outros modais de transporte que apresentam recursos essenciais.

Por sua vez, a especificidade do capital tem impacto, principalmente, no incentivo ao investimento, na medida em que reduz fortemente o valor de revenda dos ativos após a sua construção ou aquisição. O efeito é ainda mais intenso por se tratar de um conjunto de atividades em que o volume de investimento requerido é bastante superior à média dos demais serviços públicos (Corrales, 1998) Assim, quando o investimento é feito pela iniciativa privada, há elevada incerteza em relação à rentabilidade futura do projeto, que pode ser irreversivelmente comprometida pela eventual entrada de um concorrente. Adicionalmente, 
no caso de propriedade privada dos ativos, o poder de barganha entre o proprietário privado e o governo pode mudar radicalmente após o investimento ser feito.

A situação de monopólio natural não é definitiva em uma indústria, mesmo nas indústrias de rede. Inovações tecnológicas podem produzir a superação dessa condição, como de fato vem acontecendo em várias categorias de serviços públicos. De fato, para a maioria dos serviços públicos, conforme Shepherd (1990), o ciclo de vida se dá em quatro estágios:

1. Início - o sistema é inventado, sendo em geral protegido por uma patente. Esse é um período geralmente curto, mas é decisivo para a forma futura do sistema. No caso da eletricidade, por exemplo, considera-se que este primeiro estágio durou uma década e meia, entre 1870 e 1885. Para o telefone, a duração foi de meia década, entre 1875 e 1880. Já para a aviação, este período compreende os cinco anos iniciados em 1920.

2. Crescimento rápido - o sistema é criado e cresce, normalmente tomando o lugar de um serviço antigo, como no caso em que os ônibus substituíram os bondes, ou do telefone que suplantou o telégrafo. No caso do telefone, esse segundo estágio durou de 1880 até a metade deste século. Nesse estágio, as economias de escala são muito intensas.

3. Maturidade - o sistema cresce e se torna completo em termos tanto de tecnologia quanto de saturação de mercado. As economias de escala tornam-se cada vez menos significativas nesse estágio, enquanto novas tecnologias costumam ameaçar partes lucrativas do mercado.

4. Reversão para condições favoráveis à competição - o setor reverte para o processo competitivo convencional, deixando de ser um serviço público e perdendo suas características de monopólio natural.

Há setores de infraestrutura que, apesar de apresentarem configuração de monopólio natural, contêm alguns segmentos mais dinâmicos que são capazes de romper o estágio quatro, revertendo a condições relativamente favoráveis à competição, mesmo que o restante do setor mantenha-se em estágio anterior. Um importante exemplo é o serviço de telefonia. Inovações tecnológicas importantes vêm permitindo competição no setor, em especial nos serviços de longa distância. Também na área de energia elétrica, o suprimento em atacado já vem apresentando perspectivas de competição, tendo entrado no quarto estágio. Já no caso dos 
serviços públicos de saneamento, o estágio três é dificilmente ultrapassado. Nesse setor, as condições de monopólio natural são dificilmente superadas.

Em transportes, as inovações não apresentam a mesma dinâmica acelerada que, por exemplo, apresenta o setor de telecomunicações, mas vários segmentos de transportes incorporam inovações tecnológicas que potencializam sua passagem para o estágio 4, competitivo, como por exemplo, na competição entre rodovias paralelas de elevada densidade de tráfego, ou mesmo envolvendo modais distintos dentro de um mesmo mercado relevante de transportes.

A Figura 2 ilustra, de maneira não rigorosa, a posição de alguns setores no ciclo de vida típico dos serviços públicos de infraestrutura.

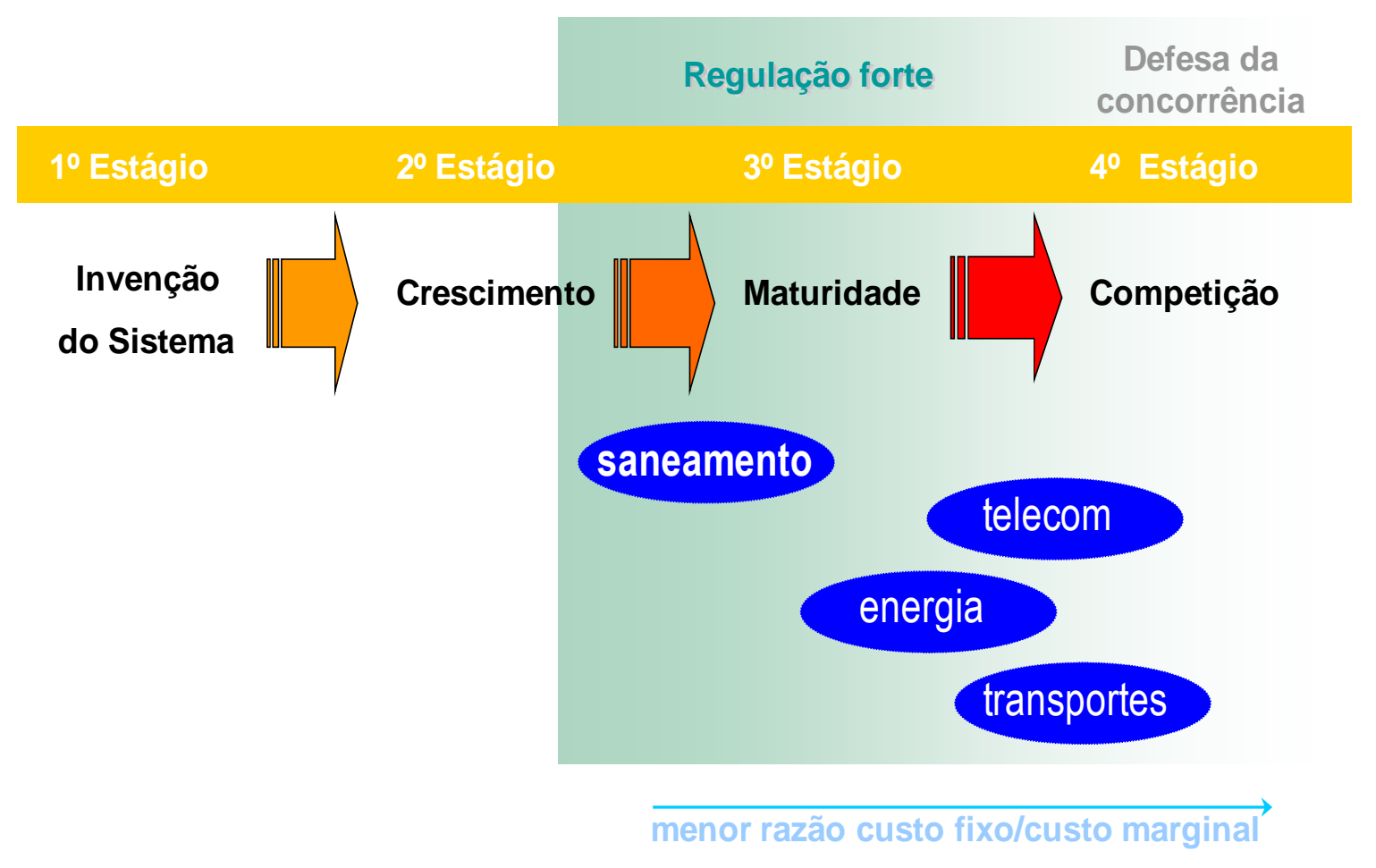

Figura 2 - Ciclo de vida dos serviços públicos de infraestrutura e posição estimada de alguns setores

Note-se que, dentro destes setores, segmentos específicos podem destoar significativamente dos demais, apresentando condições mais ou menos competitivas. Além disto, o critério principal de construção da figura é a razão entre custo fixo e custo marginal; na prática, porém, outros fatores, inclusive os de natureza institucional, podem ser relevantes para a consideração da reversão de um setor ou segmento de setor para condições competitivas. 
A reversão para a competição depende fundamentalmente da contestabilidade dos mercados, um conceito essencial na economia dos transportes. Os parágrafos a seguir discutem esse conceito a partir de Oliveira (2009).

Contestabilidade pode ser vista, informalmente, como a extensão na qual a provisão de um bem ou serviço está aberta para fornecedores alternativos. Assim, tem-se que um mercado seria contestável se novos fornecedores podem entrar (e sair) facilmente, constituindo-se como alternativas reais de consumo. A simples ameaça de tal entrada já serviria para gerar uma disciplina nas atuais firmas instaladas, que acabariam apresentando comportamento - ou conduta - distinta daquela que teriam se não houvesse a possibildade de entrada. Assim, a característica de "contestável" de um mercado serviria como um afrouxamento das condições de monopólio ou oligopólio, inibindo aumentos abusivos de preços muito acima dos custos. A livre entrada e saída derrubaria qualquer tentativa de monopolização nesse sentido.

Em termos formais, a Teoria dos Mercados Contestáveis foi desenvolvida no início dos anos 1980 pelos clássicos estudos do economista norte-americano William Baumol. Ele definiu "contestabilidade" não como um sinônimo de concorrência, mas como se referindo a uma situação na qual um provedor encara uma ameaça que considera crível de competição. A credibilidade da entrada torna-se, portanto, um conceito importante no arcabouço desenvolvido. Esses estudos permitiram chegar à conclusão de que a regulação econômica que gera barreiras à entrada de novos concorrentes e o controle de preços seria desnecessária no sentido de evitar comportamentos abusivos das empresas, dado que se houver crença na livre entrada e saída, isso por si só já restringiria as práticas das firmas estabelecidas (incumbentes) e protegeria o consumidor. Foi intensamente utilizada como argumentação para a desregulação do mercado de transporte aéreo nos Estados Unidos que culminou no Airline Deregulation Act de 1978.

Conta Martin (2000) que a Teoria dos Mercados contestáveis foi apresentada ao mundo acadêmico como um direcionamento para a conduta dos reguladores, sempre que a regulação se fizesse necessária. Os conselhos da Teoria da Contestabilidade seriam os de permitir liberdade de entrada e saída, a flexibilidade de preços e de assegurar acesso equânime aos competidores. No decorrer dos trinta anos que se seguiram ao Airline Deregulation Act (ADA) do Presidente Jimmy Carter, muito se investigou, estudou e analisou acerca do comportamento de firmas em mercados aéreos liberalizados. Muitas lições foram aprendidas. 
Sabe-se hoje em dia que os mercados aéreos não são perfeitamente contestáveis. Os próprios Baumol e o ex-presidente do Civil Aeronautics Board (CAB), Alfred Kahn, reconheceram essa evidência ex-post.

Muito pelo contrário, mesmo em regime de plena liberdade estratégica, com desregulação econômica em estágio avançado, as companhias aéreas podem sempre encontrar formas de erigir barreiras à entrada a novos competidores e de exercer poder de mercado às custas do consumidor. O bloqueio à entrada em aeroportos congestionados, por exemplo, é um dos mais importantes tipos de barreiras criadas pelas companhias aéreas. E a captura das atenções do regulador no exercício da regulação de rotina é outra forma de barreira.

\section{O papel da regulação e o financiamento}

Uma importante justificativa para a regulação é a presença de falhas de mercado, que correspondem às situações em que o livre exercício das forças do mercado desregulado não maximiza a eficiência produtiva e a eficiência alocativa. Estas falhas, que são múltiplas nos setores de infraestrutura, abrangem pelo menos os casos seguintes (Hanley, Shogren e White, 1997):

1. Poder de monopólio. Em mercados não perfeitamente competitivos, os produtores decidirão por quantidades sub-ótimas de produção, influenciando os preços de mercado a seu favor. Nesse caso, os ganhos de bem-estar (excedente) pelo produtor são inferiores às perdas de bem-estar pelos consumidores, deixando a sociedade em uma pior situação em termos de bem-estar líquido.

2. Presença de externalidades. Uma externalidade corresponde à situação em que as atividades de um indivíduo ou firma afetam a utilidade de outro indivíduo ou a função de produção de outro indivíduo. Há externalidades positivas de vários segmentos de infraestrutura na área ambiental; sobre o desenvolvimento econômico; sobre a inclusão digital; entre várias outras. E há também as externalidades de rede, pelas quais a existência de uma rede beneficia os usuários que dela participam. 
3. Não-excludabilidade. Alguns tipos de bens possuem a característica de que a exclusão do seu acesso é impossível ou muito cara, incentivando um uso superior ao de seu nível ótimo, como ocorre com o ar poluído da cidade de São Paulo. Esta falha de mercado tornou-se conhecida como a tragédia dos comuns a partir de artigo do professor de biologia Garrett Hardin (1968).

4. Não rivalidade no consumo. Um bem é não-rival quando o consumo por um indivíduo não exclui o consumo por outro indivíduo. Isso implica que o custo marginal social de oferta desse bem a um indivíduo adicional é nulo. Portanto, haverá incentivo subótimo para que os indivíduos participem da provisão do bem, já que independentemente de participaram do esforço de provisão não poderão ser excluídos do consumo. Os indivíduos que desejam consumir um bem não-rival tenderão a não participar da provisão para seguir uma estratégia de "carona".

5. Informação assimétrica. Esta ocorre em transações em que um agente desconhece informações qualitativas sobre o comportamento do outro agente, gerando resultado oposto ao esperado por uma das partes. As principais manifestações dessa categoria de falhas de mercado ocorrem nos casos de risco moral e de seleção adversa. A seleção adversa ocorre em transações em que o tipo de um dos agentes não é observável, de forma que o outro agente envolvido é obrigado a estimar seu tipo levando em consideração o comportamento de todo o mercado. A situação gera um desvio de eficiência no qual os agentes de tipo de melhor qualidade tendem a não participar do mercado. O risco moral está presente em alguns tipos de contrato em que um agente não consegue observar as ações de outro.

6. Mercados incompletos. A maximização de bem-estar só é garantida pelos mercados perfeitos quando funciona "um conjunto de mercados em que cada pessoa tem a oportunidade de trocar cada bem com cada outra pessoa", considerando-se que consumidores e produtores são racionais. Quando essa possibilidade é limitada, o que ocorre na prática em maior ou menor grau, trata-se de mercados incompletos. Este é um caso mais geral de falha de mercado. 
Várias destas falhas de mercado estão presentes no setor de transportes. Nos vários modais, o regulador zela pelo bem-estar do consumidor observando o potencial de economias de rede, lidando com o fato de que os agentes não conseguem internalizar, em suas decisões, as decisões dos outros agentes, a custos razoáveis (Seroa da Motta, 2009). No modal aéreo, por exemplo, há também uma importante questão de segurança operacional, que não pode ser observada pelo usuário a custos razoáveis, ensejando a regulação.

Uma questão relacionada diz respeito ao nascimento da regulação. Uma visão ingênua poderia atribuir o nascimento dos marcos regulatórios à simples presença de uma falha de mercado. Legisladores voltados para o interesse público constituiriam um marco regulatório em resposta a esta falha de mercado. Esta visão foi amplamente refutada pelos fatos, que dão conta que a regulação não nasce, necessariamente, em atenção ao puro interesse público, assim como o interesse público pode não ser motivação suficiente para a criação de regulação.

Uma segunda abordagem pende para o lado oposto: o interesse do regulado. A emergência de um marco regulatório, na abordagem conhecida como Teoria da Captura, estaria relacionada a interesses privados que se cristalizam em um marco regulatório. Trata-se de abordagem que, como a anterior, não corresponde aos fatos. Muitos marcos regulatórios não nasceram em decorrência de interesses privados, nem tampouco os reguladores setoriais são necessariamente capturados por interesses econômicos específicos e bem delimitados.

O desenvolvimento mais recente da teoria econômica da área regulatória trata de motivações bem mais complexas para a emergência de um marco regulatório, assim como de um intrincado processo evolutivo que conjuga o interesse público, o interesse econômico dos regulados e ainda o de um conjunto de interesses, difusos ou organizados, de atores interessados da sociedade. 
A Figura 3 ilustra a evolução da Teoria Econômica da Regulação, passando pela teoria do interesse público; a teoria da captura; e a Teoria Econômica da Regulação.

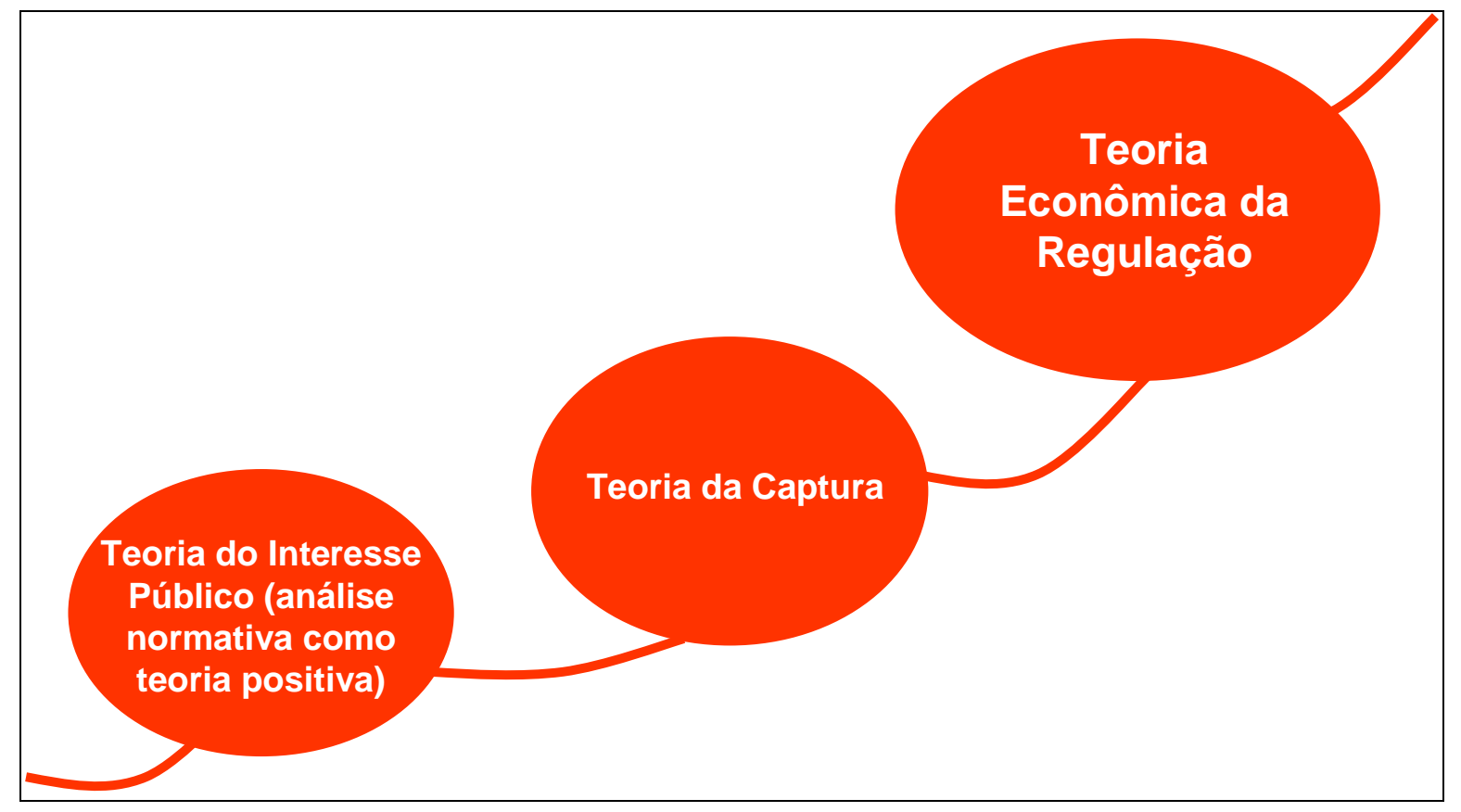

Figura 3 - Ilustração sobre a evolução da Teoria Econômica da Regulação

Fonte: elaboração com base em Viscusi et al (2005).

É neste contexto que deve ser entendido o nascimento e a evolução recente dos marcos regulatórios dos transportes no Brasil. Um importante aspecto é que a regulação setorial nasceu, nos anos noventa, fragmentada em seus diversos modais. As leis 1.615 de 1.999 e 3.093 de 2.000 criaram a Agência Nacional de Transportes Terrestres (ferrovias e rodovias) e a Agência Nacional de Transportes Aquaviários (portos e navegação). Já a lei de criação da ANAC (Agência Nacional de Aviação Civil), a lei 11.182, para o transporte aéreo, surgiu apenas em 2005. Há, ainda, as entidades reguladoras subnacionais, que também têm responsabilidades na área de transportes.

É importante notar que a regulação guarda uma relação não linear com o financiamento dos serviços de transportes e de infraestrutura. A ausência de regulação, em presença de falhas de mercado, tende a trazer dificuldades de financiamento, tendo em vista os elevados riscos da operação desregulada quando o funcionamento dos mercados não produz a melhor situação em termos de eficiência produtiva e/ou alocativa. Por outro lado, a regulação introduz, em si, 
riscos importantes. Entendida como solução de "second best" (ou segundo melhor), introduz suas próprias ineficiências e seus próprios problemas. A quantidade ótima de regulação é, assim, sujeita a discussões intermináveis e acaba sendo difícil de determinar, na prática. Sabese apenas, em geral, o significado de desregulação e dos exageros regulatórios mais comuns.

Para minimizar estes problemas, o desenho das instituições regulatórias é um fundamental para a efetividade da regulação e para a redução do seu risco, afetando o financiamento dos serviços. Muitas vezes, este desenho pode envolver a criação de órgãos do estado, separados como autarquias especiais, sujeitos a uma governança separada dos demais componentes do Estado, e com uma tomada de decisões sujeita a incentivos diferentes. Elementos como a natureza do órgão regulador, o processo de condução de dirigentes ou conselheiros, o tamanho do conselho decisor, as formas de controle social, o mecanismo de financiamento da entidade, os requerimentos de publicidade e transparência, entre outros, importam de maneira decisiva para os resultados do processo regulatório.

\section{Financiamento da infraestrutura}

É em função da presença destas especificidades e de importantes falhas de mercado que a governança, a regulação e o ambiente institucional se tornam elementos centrais na área de infraestrutura. A literatura sobre contratos público-privados tende fortemente à área de Nova Economia Institucional, como em North (1991) ou Williamson (1985), ou alternativamente, ao campo de Economia e Direito, como em Cooter e Ulen (2003) ou, no Brasil, Pinheiro e Saddi (2005). De acordo com Farina, Azevedo e Saes (1997), o campo da Nova Economia Institucional pode ser caracterizado como na Figura 1. Note-se que, no nível da estrutura de governança, como em Williamson, são relevantes os custos de transação. 


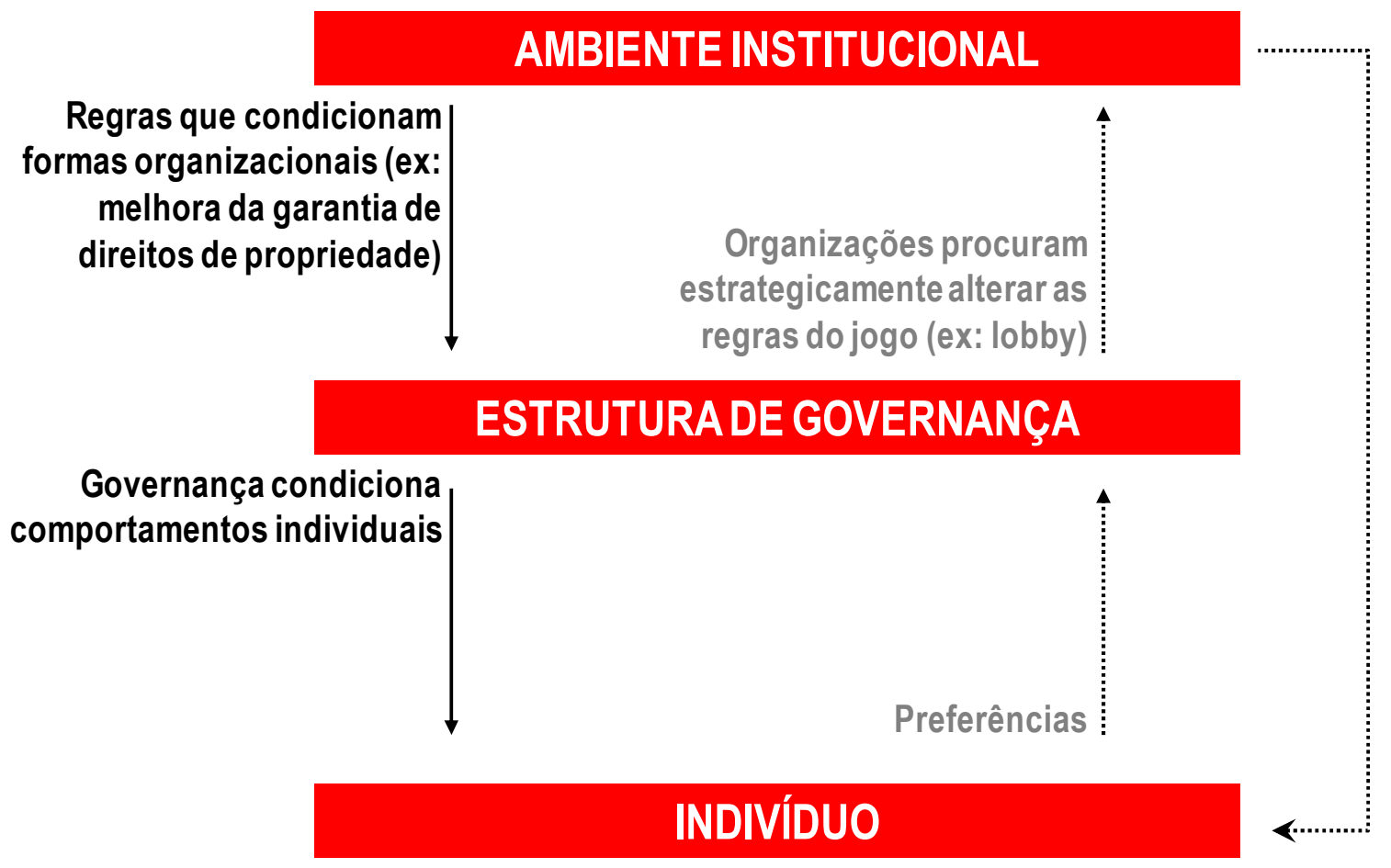

\section{Figura 1 - Esquema do campo da Nova Economia Institucional}

Fonte: elaboração a partir de Farina, Azevedo e Saes (1997)

A qualidade do ambiente institucional afeta diretamente a propensão ex ante a investir em qualquer atividade econômica. O grau de garantia dos direitos de propriedade é um elemento essencial do ambiente institucional de uma economia de mercado, permitindo a extração de benefícios através do processo de transação. Falhas na proteção destes direitos causam fortes reduções na propensão ex ante ao investimento e ao financiamento do investimento, alterando seus custos. Em infraestrutura, esta característica é ainda mais importante, tendo em vista que há elevados custos de transação envolvidos na competição pelas licenças e concessões que dão acesso aos mercados relevantes de infraestrutura.

As questões institucionais e organizacionais envolvidas fazem com que a complexidade econômica dos segmentos de infraestrutura seja diretamente proporcional à complexidade dos processos de financiamento. Os diversos países mantêm esquemas variados de financiamento à infraestrutura, que correspondem a instituições no sentido de North, e que delimitam estruturas de governança. 
Há, ainda, a possibilidade uma falha de mercado relativa ao grau em que os mercados são completos, ou seja, se oferecem todo tipo de seguro contra riscos, e de financiamentos adequados. O mercado brasileiro de capitais constitui exemplo de mercado incompleto, na medida em que parte relevante das necessidades de financiamento vinculadas a empreendimentos de longo prazo tem sido suprida, nas últimas décadas, por fundos originados da instituição oficial de fomento, o BNDES. A dependência histórica das fontes oficiais e de fomento foi reduzida a partir dos anos noventa, mas ainda se mantém elevada.

O mercado financeiro e de capitais não oferece suporte suficiente ao grande volume de projetos de longo prazo, e não está preparado para assumir alguns tipos de risco, sem garantias elevadas. Em presença de forte assimetria informacional na concessão de financiamentos, a defesa dos agentes financiadores costuma vir na forma de exigência de garantias, que podem ser reais (como a hipoteca, alienação fiduciária, o penhor e a caução), ou pessoais (aval e fiança). A dificuldade ou o custo envolvido na obtenção dessas garantias pode fazer com que empresas com projetos rentáveis e com disposição para o repagamento dos financiamentos possam não ter acesso a eles. Neste contexto, as garantias se tornam um importante fator inibidor da competitividade de vários setores importantes, assim como uma forte restrição aos investimentos em setores de infraestrutura. Esquemas públicos voltados para a oferta de fomento existem em vários países, inclusive no Brasil, mas de forma insuficiente.

No ambiente de financiamento de projetos, a modalidade consolidada é o project finance (Finnerty, 1996), que limita a governança da transação ao projeto individual, limitando seus riscos para garantir a financiabilidade. Em muitas jurisdições, o project finance envolvendo ativos públicos ou regulados é sujeito a legislação específica de parceria público-privada (PPP), uma instituição com fortes impactos sobre a prática do project finance.

As legislações nacionais de PPP podem ser inseridas no contexto de seu ambiente institucional, que pode ser definido como em North 1991: conjunto de regras formais e informais que delimitam a interação política, econômica e social. Em North 1991, o grau de complexidade do mundo gera diferentes ambientes institucionais para viabilizar as transações, e a forma de organização desse ambiente tem impacto sobre o desempenho econômico global, assim como sobre aspectos específicos, em particular sobre o financiamento da infraestrutura. 
Como exemplo, no Brasil esta legislação inclui categorias que podem ser identificadas como concessão comum, administrativa ou patrocinada. No primeiro caso, é regida pela lei 8.987 de 1995, e nos demais pela lei 11.079 de 2004. Essas duas se somam e são complementadas pela Lei das Licitações (8.666/93). Em termos gerais, as primeiras atendem a projetos autosustentáveis com fluxos financeiros oriundos de tarifas, enquanto a lei que ficou conhecida como "lei das PPP" atende a projetos onde é necessário o aporte de recursos públicos. Somese a isto o regime jurídico geral, havendo ainda a discussão sobre a tradição jurídica e o mercado de capitais, além de um grande número de aspectos relacionados ao mercado de crédito e às leis sobre falência.

No caso brasileiro, na prática, a disciplina contratual público-pública e público-privada vem permitindo um aumento significativo do leque de possibilidades relacionadas à prestação e ao financiamento dos serviços de infraestrutura, viabilizando novas formas de cooperação entre uma grande variedade de agentes públicos e privados.

Ainda como exemplo destas instituições de parceria e financiamento no caso brasileiro, tomese a Figura 2, que apresenta uma carteira hipotética de projetos de infraestrutura, construída a partir de um conjunto de projetos aleatoriamente gerados a partir de dois atributos: retorno privado, definido, por exemplo pela Taxa Interna de Retorno do projeto sem considerar suas externalidades positivas, e o retorno social, que agrega ao primeiro a geração de externalidades derivadas da execução do projeto de infraestrutura de transportes. No eixo vertical, foi representada a taxa de retorno privado dos projetos. No eixo horizontal, a taxa de retorno social dos projetos, que representa o volume de externalidades geradas por unidade de investimento. Cada esfera representa um projeto, sendo que o volume da esfera pode ser tomado como o tamanho relativo do empreendimento. 


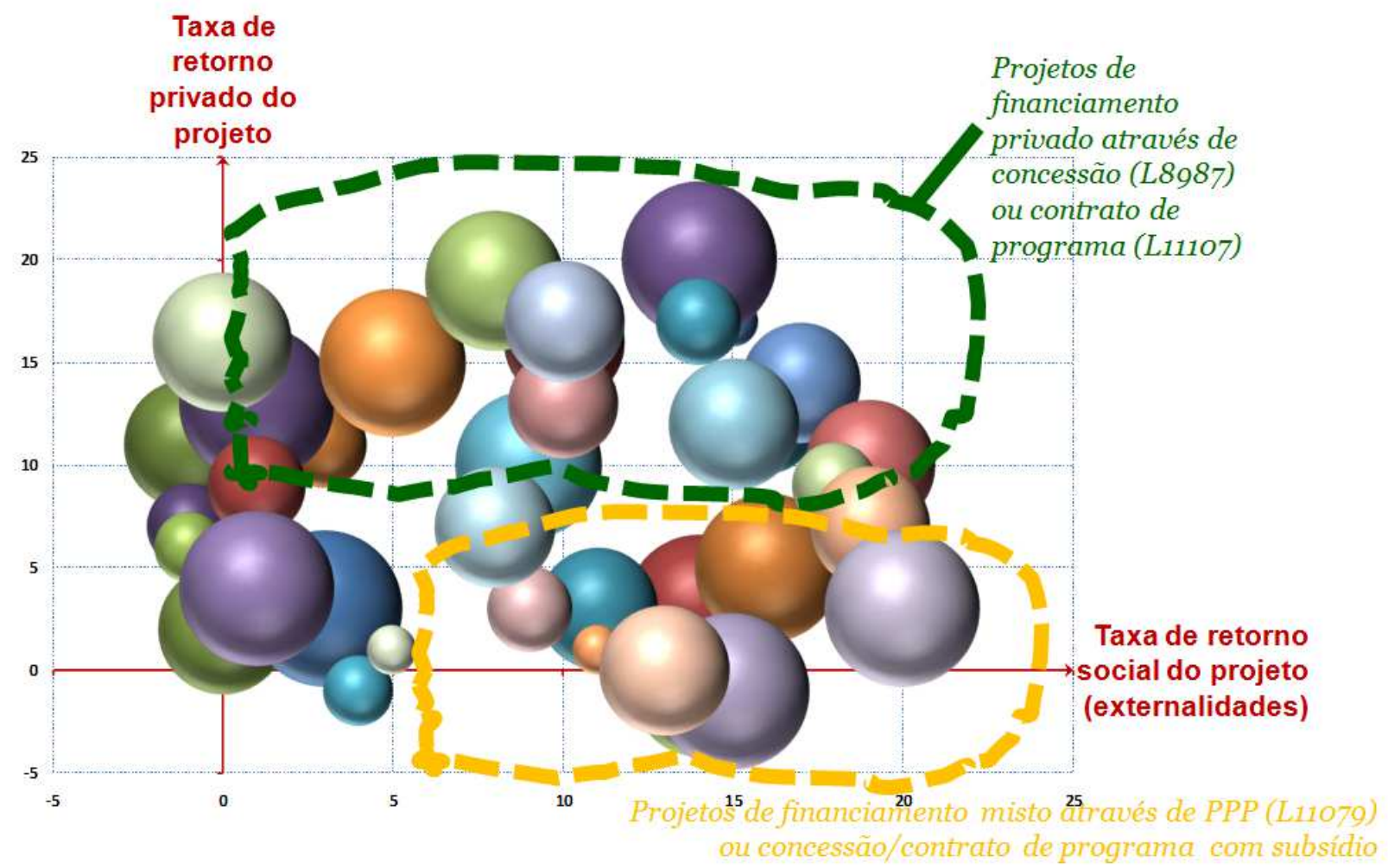

Figura 2 - Uma carteira hipotética de projetos de infraestrutura

Os melhores projetos são os que estão mais a nordeste no primeiro quadrante, pois apresentam uma feliz combinação entre alto retorno privado e alto retorno social. Infelizmente, estes projetos, que não demandam recursos públicos, mas trazem grandes benefícios à coletividade, são pouco numerosos. Estes projetos são candidatos à operação por concessão comum, da lei 8.987/95, ou lei das concessões.

Os projetos que próximos do eixo horizontal, mas localizados bem a leste do eixo vertical, são projetos de bom retorno social, mas com baixo retorno privado. Para estes, o instrumento típico tende a ser a lei 11.079/04, das Parcerias Público-Privadas. Estes contratos também podem operar com subsídio público, tendo em vista que, embora de interesse social, não apresentam retorno privado suficiente para estimular a execução autônoma do projeto por investidores particulares.

Os projetos de infraestrutura contam, em muitos casos, com dotações orçamentárias de vários níveis de governo, assim como financiamento público em caráter de fomento, por instituições oficiais, e subsídios e recursos orçamentários disponibilizados com este mesmo fim. Por exemplo, no próprio setor de transportes, o financiamento do segmento de aeroportos no 
Brasil foi classificado em Campos Neto e Souza (2011) como "fiscal” e "próprio da infraero", chegando à conclusão que a os investimentos em aeroportos no Brasil são altamente dependentes do setor público - e a operadora Infraero dependente desses investimentos, mesmo com elevada capacidade de geração interna de recursos. Nos anos entre 2003 e 2010, $61 \%$ das aplicações de 8,8 bilhões de reais em investimentos públicos no setor aéreo foram originados do orçamento fiscal.A curva de aprendizado dos governos na área de parcerias público-privadas vem avançando, principalmente no caso de alguns governos estaduais, e vários projetos vem amadurecendo. Adicionalmente, o limite de contratação de parcerias pelos entes subnacionais foi ampliado com a modificação do art. 28 da Lei das PPP. Este, originalmente, penalizava com a suspensão de transferências voluntárias federais o ente que tivesse uma soma de despesas de caráter continuado derivada do conjunto das parcerias, ou soma das despesas anuais dos contratos vigentes nos dez anos subseqüentes, superior a $1 \%$ da receita corrente líquida do exercício. Em agosto de 2009, o limite foi ampliado para 3\%, excluídas as estatais não dependentes. Naturalmente, o novo dispositivo aumenta os riscos ao setor público, o que é um aspecto relevante no atual quadro de deterioração da saúde fiscal da União, mas traz a vantagem de criar espaço para um maior número de projetos de PPP no ambiente subnacional.

Há, portanto, algumas boas notícias na área de financiamento de projetos de infraestrutura e de segmentos relacionados. Permanecem, ainda, desafios importantes: entre eles, a politização do ambiente regulatório, que aumenta o risco de longo prazo dos projetos, e a deterioração do orçamento público, que praticamente desabilita o papel do Estado brasileiro como investidor direto ativo nos mercados de infraestrutura, exceto em momentos excepcionais da arrecadação tributária, como foram os primeiros anos do PAC. Para garantir um aumento da taxa de investimento em ativos de infraestrutura, resta aos governos o papel de resolver falhas de coordenação e outras falhas de mercado, atuando inclusive nas condições de financiamento dos projetos e nas variáveis institucionais relevantes. 


\section{Participação privada e investimentos estrangeiros}

Em toda a discussão sobre financiamento de infraestrutura aparece como questão central a participação privada, mesmo quando a obrigação da provisão do serviço é do setor público. No caso da infraestrutura portuária não é diferente: longas discussões opõem, muitas vezes de modo simplista, a operação pública e privada.

De fato, múltiplos modelos podem ser encontrados. No caso da infraestrutura portuária:

"Regarding infrastructure financing, we can find many different situations across the world (see Box 4). In particular, it is possible to identify a municipal model of port, such as those in North Europe (Netherlands, Belgium, Germany); a state model, such as those used in South Europe and South America, in which central governments control and finance all main ports; and a private model of port, where investment costs are paid by private firms or by port authorities from the resources obtained from charges to port users. This last model is more common in countries with a British tradition, which regards ports as commercial rather than public institutions" (Trujillo and Nombela, 1999).

Outra questão importante sobre o financiamento da infraestrutura diz respeito aos investimentos diretos estrangeiros. A importância dos investimentos diretos na infraestrutura brasileira passa a ser bidirecional: são relevantes os ingressos estrangeiros no país, que contribuem para o financiamento da expansão de nossa infraestrutura, quanto os fluxos brasileiros no exterior.

A entrada de investimentos diretos na área de infraestrutura é uma importante fonte de capitais para o desenvolvimento deste setor. A UNCTAD, por exemplo, em seu relatório World Investment Report de 2008, que é dedicado ao papel das empresas transnacionais no desafio da infraestrutura, apontou que "uma forma de atacar os problemas em infraestrutura e serviços relacionados nos países em desenvolvimento é mobilizar IDE e outras formas de participação de empresas transnacionais para suplementar e complementar as atividades das empresas públicas e privadas domésticas de infraestrutura" (WIR 2008, tradução livre, p. 87). 
Em termos quantitativos, a base de dados de infraestrutura do Banco Mundial aponta que 29\% do valor dos investimentos comprometidos em indústrias de infraestrutura nos países emergentes no período 1996-2006 foram investimentos estrangeiros. Na América Latina, este percentual é inferior, de cerca de $20 \%$, o que indica que os países desta região poderiam contar, de forma bem mais significativa, com uma fonte de financiamento que vem sendo mais relevante na expansão da infraestrutura de outros países em desenvolvimento.

O maior investidor estrangeiro em infraestrutura no mundo atual é o Reino Unido, que possuía, em 2006, um estoque de cerca de 208 bilhões de dólares investidos nesta área. Em seguida vem a França, com mais de 100 bilhões, a Espanha (90 bilhões) e os EUA e o Canadá, respectivamente com 49 e 42 bilhões investidos, conforme a base de dados da UNCTAD. O Brasil já foi um importante receptor de investimentos diretos na área de infraestrutura, mas bem antes da crise de 2008 já vinha perdendo posições nesta área, conforme mostra a Figura 3.

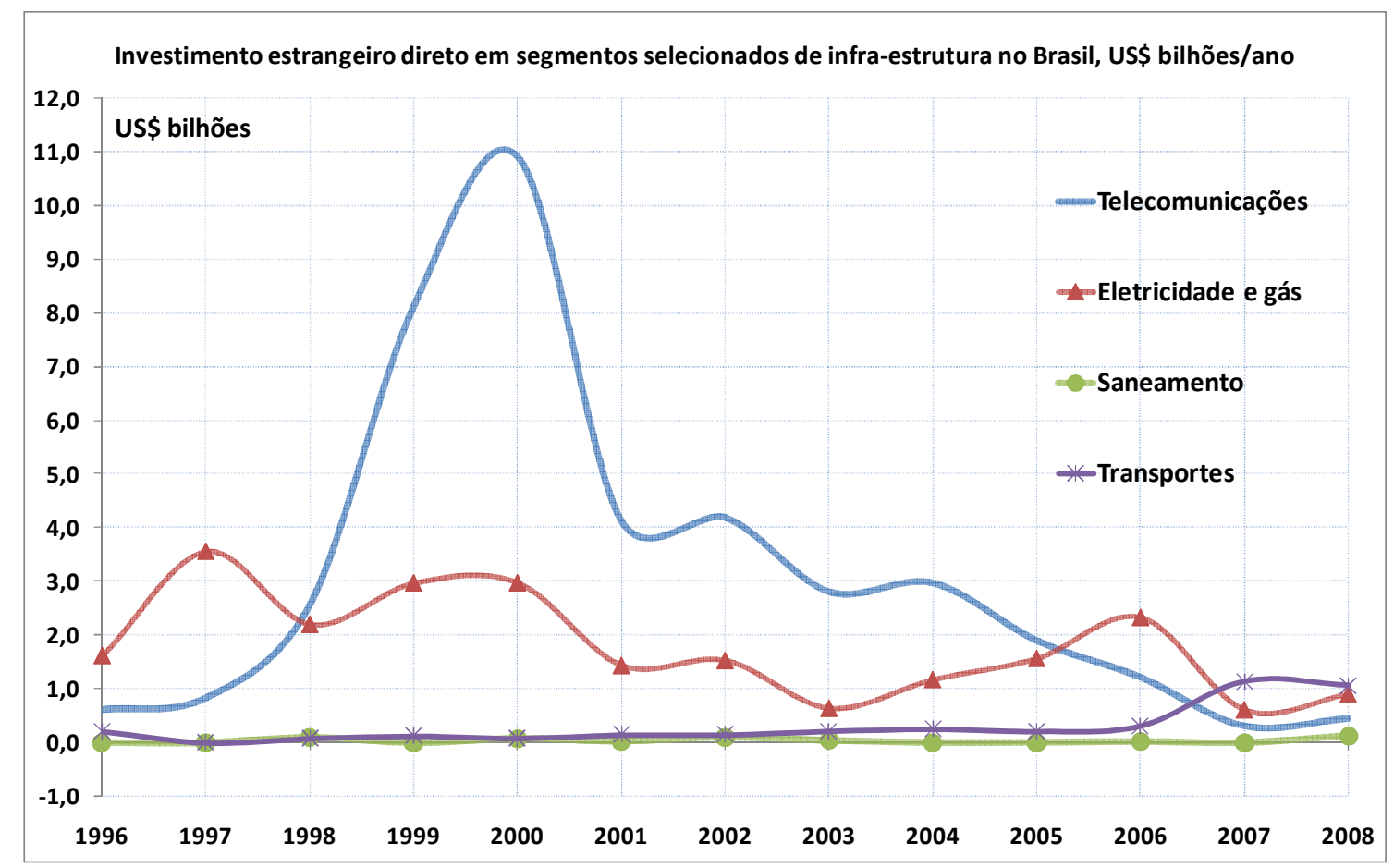

Figura 3 - Evolução do Investimento Direto Estrangeiro em infraestrutura no Brasil, 1996-2008

É possível que uma das causas da desaceleração dos investimentos possa estar relacionada à abordagem das políticas nacionais na área regulatória, hoje marcadas por mais interferência 
política e intervencionismo, com menor foco na eficiência, e na competição, mesmo onde esta é desejável.

Conforme mostra a Figura 3, o pico dos investimentos estrangeiros na infraestrutura brasileira se deu no fim dos anos noventa, principalmente no setor de telecomunicações, com a desestatização do sistema Telebrás e o início da oferta de faixas de freqüência no espectro eletromagnético. Estes investimentos contribuíram para um importante salto na cobertura das redes de telecomunicações entre os domicílios brasileiros. Nos últimos anos, entretanto, os investimentos estrangeiros em infraestrutura apresentam contribuição bem mais modesta. É surpreendente que esta queda no volume de investimentos tenha ocorrido em meio ao momento de espetacular expansão da economia mundial. O setor de transportes experimentou ampliação, mas ainda em nível relativamente baixo. Nestes últimos anos da década de 2000, a participação da infraestrutura no investimento direto estrangeiro total vem se situando em nível relativamente baixo em comparação com os últimos anos, como mostra a Figura 4, sugerindo um elevado potencial de retomada e ampliação.

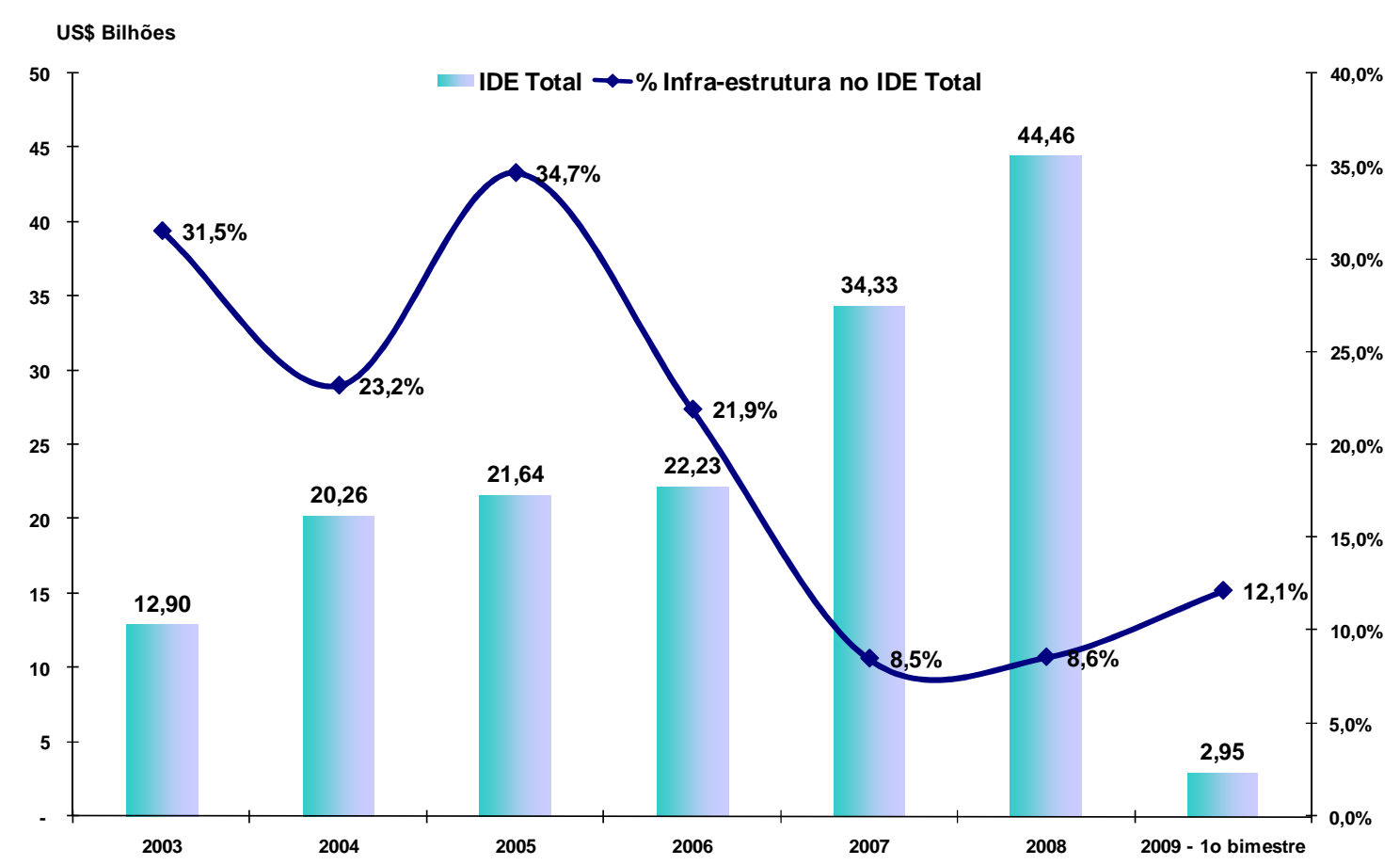

Figura 4 - Participação do setor de infraestrutura no investimento direto estrangeiro total, $\%$

Fonte: Banco Central do Brasil, com elaboração própria 


\section{Comentários finais}

O financiamento da infraestrutura e, em particular, da infraestrutura de transportes, não é tarefa automática nem simples. Não é automática porque os mercados falham em prover o nível adequado de financiamento, por vários motivos. Não é simples porque, mesmo quando são estabelecidos arranjos e parcerias voltados para a provisão de financiamento, os esquemas estabelecidos têm impactos não neutros sobre diversos tipos de agentes econômicos e sobre a sociedade em geral.

Assim, a discussão do financiamento tem que evitar soluções simplistas, ideológicas e voluntaristas; antes, é necessário buscar soluções tecnicamente estudadas, embasadas na ampla literatura acadêmica sobre infraestrutura, além de análises fundamentadas em dados que, para a evolução do setor, devem ser crescentemente tornados públicos. A literatura contém exemplos de análises de eficiência a partir de bases de dados (Bertolotto e Soares de Mello, 2011; Acosta, Silva e Lima, 2011; e Santos, Cardoso e Moita, 2011), mas certamente há uma imensa lacuna a ser preenchida no tocante à disponibilidade de dados para avaliações acadêmicas, regulatórias e estratégicas no setor de transportes no Brasil.

O papel da regulação deve estar sempre sujeito a avaliação e revisão, tendo em vista as dinâmicas tecnológica, empresarial e institucional que promovem mudanças no ambiente dos setores de infraestrutura. É preciso reconhecer os segmentos de baixa contestabilidade, como é típico de alguns mercados de transportes, e também as características diferenciadas dos segmentos mais duros da infraestrutura, envolvendo, por exemplo, infraestrutura essencial (essential facilities). Uma importante recomendação de políticas públicas derivada desta constatação diz respeito ao fortalecimento da regulação setorial aplicando-se políticas regulatórias distintas para segmentos que apresentam características econômicas diferentes, aproveitando o potencial de eficiência, alocativa e produtiva, derivado da competição, onde possível, e regulando-se com vistas ao avanço em direção a um avanço no ciclo de vida do serviço, potencializando a introdução futura de competição através de desregulamentação. Há, também, importantes questões sobre o desenho do aparato regulatório e a governança das entidades reguladoras. Não se trata, entretanto, de tarefa trivial. 


\section{Referências}

Acosta, C. M. M., Silva, A. M. V. A. e Lima, M. L. P. (2011) Aplicação de análise envoltória de dados (DEA) para medir eficiência em portos brasileiros. Journal of Transport Literature, vol. 5, n. 4 , pp. 88-102.

Alves, C. J. P. e Amaral, F. C. F. (2012) A situação da infraestrutura aeroportuária na região norte e seu potencial apoio à aviação regional. Journal of Transport Literature, vol. 6, n.1.

Andrés, L. A., Guasch, J. L., Haven, T. e Foster, V. (2008) The impact of private sector participation in infrastructure: lights, shadows, and the road ahead. Washington, DC: The International Bank for Reconstruction and Development / The World Bank.

Baumol, W. J. On Proper Cost Tests for Natural Monoopoly in a Multiproduct Industry. In: Baumol, W. J. Microtheory: Applications and Origins. Cambridge, MA: The MIT Press, 1986.

Bertoloto, R. F. e Melo, J. C. C. B. S. (2011) Eficiência de portos e terminais privativos brasileiros com características distintas. Journal of Transport Literature, vol. 5, n. 2, pp. 4-21.

Bertussi, G. L. e Ellery Junior, R. (2012) Infraestrutura de transporte e crescimento econômico no Brasil. Journal of Transport Literature, vol. 6, n.4.

Banco Interamericano de Desarrolo (1997) Private Participation in Infrastructure Projects: Determinants of the Observed Contractual Arrangements - Terms of Reference. Banco Interamericano de Desarrolo. Proyecto Red de Centros de Investigación, Anexo A.

Blum, U. (1998) Positive Externalities and the Public Provision of Transportation Infrastructure: An Evolutionary Perspective. Journal of Transportation and Statistics, October.

Braeutigam, R. R. (1989) Optimal Policies for Natural Monopolies. In: SCHMALENSEE, R. and R. D. Willig (ed). Handbook of Industrial Organization Volume II. Elsevier Science Publishers.

Calderón, C. e Serven, L. (2004) The effects of infrastructure development on growth and income distribution. Banco Central de Chile Documentos de Trabajo - No 270 - Septiembre.

Cooter, R. e Ulen, T. Law \& Economics. Pearson Addison Wesley, 2003 - 4a edição.

Corrales, M. E. (1998) La regulación en períodos de transición: el caso de los servicios de agua potable y saniamiento en América Latina. In: Barrionuevo Filho, A. Lahera P., E. (eds). Qué hay de nuevo en las regulaciones? Telecomunicaciones, electricidad y agua en América Latina. Eudeba/CLAD.

Demant, M. A. R. (2011) Infraestrutura aeroportuária e o desenvolvimento do tráfego aéreo regional no Brasil. Journal of Transport Literature, vol. 5, n. 1, pp. 124-160.

Farina, E. M. M. Q., Azevedo, P. F. e Saes, M. S. M. (1997) Competitividade: Mercado, Estado e Organizações. São Paulo: Singular.

Finnerty, J. D. (1996) Project Finance: Asset-Based Financial Engineering. John Wiley \& Sons.

Hanley, N., Shogren, J. F. e White, B. (1997) Environmental Economics in Theory and Practice. London: Macmillan.

Hardin, G. (1968) The Tragedy of the Commons. Science, vol. 162, pp. 1243-1248, dezembro.

Martin, S. (2000) The Theory of Contestable Markets. Advanced Industrial Economics, Supplementary Material. Second edition, Blackwell Publishers.

North, D. (1991). Institutions. Journal of Economic Perspectives, 5, Winter, pp.97-112. 
Oliveira, A. V. M. e Turolla, F. A. (2008) O problema dos recursos essenciais (essencial facilities) na infraestrutura. Conjuntura da Infraestrutura, São Paulo, v. 3, p. 16 - 17, 01 mar.

Oliveira, A. V. M. (2009) Transporte aéreo: economia e políticas públicas. São Paulo: Pezco Editora.

Pinheiro, A. Ca. e Saddi, J. (2005) Direito, Economia e Mercados. Rio de Janeiro: Elsevier Campus.

Sader, F. (2000) Attracting Foreign Direct Investment Into Infrastructure: Why is it So Difficult? Occasional Paper number 12. Washington: The World Bank/FIAS - Foreign Investment Advisory Facility.

Santos, J. T. A. N., Cardoso, P. e Moita, M. H. V. (2011) Atributos de Paralisação como Indicador de Produtividade da Operação Portuária de Cabotagem em Manaus. Journal of Transport Literature, vol. 5, n. 4, pp. 70-87.

Seroa da Motta, R. (2009) Apresentação. In: OLIVEIRA, A. V. M. O. Transporte aéreo: economia e políticas públicas. São Paulo: Pezco Editora.

Shepherd, W. G. (1990) The Economics of Industrial Organization. $3^{\circ} \mathrm{ed}$, Prentice Hall.

Trujillo, L. e Nombela, G. (1999) Privatization and regulation of the seaport industry.

Unctad - United Nations Conference on Trade and Development (2008). World Investment Report 2008: Transnational Corporations, and the Infrastructure Challenge. UNCTAD: Geneva.

Viscusi, W. Kip, Harrington, J. E. e Vernon, J. M. (2005) Economics of Regulation and Antitrust. Cambridge, MA: The MIT Press. 4a edição.

Williamson, O. E. (1985) The economic institutions of capitalism: firms, markets, relational contracting. New York: The Free Press. 